\title{
DUCT RETROFIT STRATEGY TO COMPLEMENT A MODULATING FURNACE
}

\author{
JOHN W. ANDREWS
}

October 2002

Prepared for:

Office of Building Technologies

State and Community Programs

U.S. Department of Energy

Washington, DC 20585

Under Contract No. DE-AC02-98CH10886 


\section{DISCLAIMER}

This report was prepared as an account of work sponsored by an agency of the United States Government. Neither the United States Government nor any agency thereof, nor any employees, nor any of their contractors, subcontractors or their employees, makes any warranty, express or implied, or assumes any legal liability or responsibility for the accuracy, completeness, or any third party's use or the results of such use of any information, apparatus, product, or process disclosed, or represents that its use would not infringe privately owned rights. Reference herein to any specific commercial product, process, or service by trade name, trademark, manufacturer, or otherwise, does not necessarily constitute or imply its endorsement, recommendation, or favoring by the United States Government or any agency thereof or its contractors or subcontractors. The views and opinions of authors expressed herein do not necessarily state or reflect those of the United States Government or any agency thereof.

Available electronically at-

http://www.doe.gov/bridge

Available to U.S. Department of Energy and its contractors in paper from-

U.S. Department of Energy

Office of Scientific and Technical Information

P.O. Box 62

Oak Ridge, TN 37831

(423) $576-8401$

Available to the public from-

U.S. Department of Commerce

National Technical Information Service

5285 Port Royal Road

Springfield, VA 22131

(703) $487-4650$

8 Printed on recycled paper 


\title{
DUCT RETROFIT STRATEGY TO COMPLEMENT A MODULATING
} FURNACE

\author{
John W. Andrews \\ Brookhaven National Laboratory \\ Upton, NY 11973
}

October 2002

(Original draft December, 2001)

\begin{abstract}
Recent work by the author and others indicates that conductive heat losses in ductwork will usually increase significantly when airflow rates are reduced, as will happen when a modulating furnace is installed in place of an existing high-output unit. A duct retrofit strategy is proposed that to mitigate these losses. The strategy involves the use of insulating sleeves installed inside the supply runout ducts.
\end{abstract}




\section{TABLE OF CONTENTS}

Introduction............................................................................ 1

Upgrading the Duct System..................................................... 1

Proportions of Duct Surface in Trunks and Runouts......................... 3

Internal vs. External Insulation............................................... 4

Heat Loss from a Benchmark Duct System...................................... 4

Impact of Duct and Equipment Parameters..................................... 5

Modulating Furnace in the As-Found System................................. 5

Interior Insulation in the Supply Runout Ducts............................... 6

Can the Duct System Be Made Better Still?..................................... 7

Conceptual Design of a Practical System for Internal Insulation Retrofit.......... 8

Conclusion................................................................. 9

Acknowledgment............................................................. 9

References....................................................................... 9

Appendix. Heat Loss From a Benchmark Duct System........................... 10

Thermal Loss Calculations.......................................................... 10

Leakage Impacts................................................................ 12

\section{LIST OF FIGURES}

Figure 1 Insulating Sleeve Installation Schematic............................ 14

\section{LIST OF TABLES}

Table 1 Distribution of Supply Duct Surface Areas Outside Conditioned Space in Eleven Single Family Homes. 



\section{INTRODUCTION}

Some recent work (Walker 2001, Andrews 2002) has indicated that installing a modulating furnace in a conventional duct system may, in many cases, result in a significant degradation in thermal distribution efficiency. The fundamental mechanism was pointed out nearly two decades ago (Andrews and Krajewski 1985). The problem occurs in duct systems that are less-than-perfectly insulated (e.g., R-4 duct wrap) and are located outside the conditioned space. It stems from the fact that when the airflow rate is reduced, as it will be when the modulating furnace reduces its heat output rate, the supply air will have a longer residence time in the ducts and will therefore lose a greater percentage of its heat by conduction than it did at the higher airflow rate.

The impact of duct leakage, on the other hand, is not expected to change very much under furnace modulation. The pressures in the duct system will be reduced when the airflow rate is reduced, thus reducing the leakage per unit time. This is balanced by the fact that the operating time will increase in order to meet the same heating load as with the conventional furnace operating at higher output and airflow rates. The balance would be exact if the exponent in the pressure vs. airflow equation were the same as that in the pressure vs. duct leakage equation. Since the pressure-airflow exponent is usually $\sim 0.5$ and the pressure-leakage exponent is usually $\sim 0.6$, the leakage loss as a fraction of the load should be slightly lower for the modulating furnace. The difference, however, is expected to be small, determined as it is by a function with an exponent equal to the difference between the above two exponents, or $\sim 0.1$.

The negative impact of increased thermal conduction losses from the duct system may be partially offset by improved efficiency of the modulating furnace itself. Also, the modulating furnace will cycle on and off less often than a single-capacity model, and this may add a small amount (probably in the range 1\% - 3\%) to the thermal distribution efficiency. ${ }^{1}$

Nevertheless, the effect of furnace modulation on thermal distribution efficiency, both as calculated and as measured in the laboratory, is quite significant. Although exact quantification of the impact will depend on factors such as climate and the location of the ducts within the structure, impacts in the $15 \%-25 \%$ range are to be expected for ducts located outside the conditioned space, as most residential duct systems are. This is too large a handicap to ignore.

\section{UPGRADING THE DUCT SYSTEM}

This report is based on the conclusion drawn from the above discussion, that it is usually a mistake simply to install a modulating furnace in a duct system that was sized for a larger unit, without giving any thought to the implications of this action on the performance of the overall system. A better plan would be to use the occasion of furnace replacement as an opportunity to interest the customer in a comprehensive system upgrade, including the ductwork. Ideally, the home should be left with a system that is

\footnotetext{
${ }^{1}$ ASHRAE Standard $152 \mathrm{P}$ imposes a $2 \%$ to $5 \%$ penalty for cycling losses on seasonal distribution efficiency. The $1 \%$ to $3 \%$ range suggested here is based on the likelihood that the modulating furnace will reduce cycling but not eliminate it completely.
} 
as close as possible to what would have been installed in a new home had there been complete design freedom. However, economic constraints usually preclude a complete replacement of the existing duct system. There may be a useful role, therefore, for a partial upgrade of the duct system. Of course, duct repairs - including both sealing and insulation - are often a good idea even in the absence of furnace modulation. One thing that modulating equipment does is shift the balance of priorities more in the direction of insulation relative to sealing.

Difficulties encountered in efforts to seal and insulate existing ductwork include:

- Ducts are in locations that are unpleasant, difficult, or impossible to reach.

- Existing insulation gets in the way of efforts to seal the ducts.

- Sealing, if done by hand, is a relatively slow process even under ideal conditions. Aerosol sealing in existing residential duct systems involves some added-cost steps, such as isolating equipment heat exchangers and the system fan, that can be avoided in new systems.

- Adding insulation, especially beyond R-4, may be limited by duct placement close to structures and multiple supports, and its effectiveness may be reduced by unintentional or unavoidable compression of the insulating material.

If sealing difficulties were the only issue, one could perhaps make a blanket recommendation that aerosol sealing be used. However, in cases where insulation is also of key importance, additional options may bear looking into.

This report describes one such possible approach. Since it has not yet been tried even experimentally, it is premature to make an estimate of its probable merit. Rather, it is introduced as a conceptual approach to serve as a benchmark for any detailed cost/benefit calculations that would surely be part of any attempt to reduce it to practice.

The proposed strategy is based on the fact that many if not most duct systems today are of the "trunk and branch" design. That is, one or more main trunk ducts, usually rectangular in cross section, emerge from the central heating equipment. From these trunk ducts, so-called "runouts," usually round in cross section, connect the main trunks to the individual supply registers. These runouts tend to be numerous enough that their surface area generally exceeds the surface area of the trunk ducts.

These considerations have led to the suggestion that insulating sleeves, installed internally to the runout ducts, could play a significant role in improving system performance, especially in systems where a modulating furnace is to be installed. The reasons for thinking this might be a good idea for such situations are:

- Internal insulation is more effective than external insulation, per unit of thickness, in runout ducts of diameters typical in American housing.

- The expectation that a modulating furnace will be running at reduced flow rates most of the time should make the reduction in cross section more acceptable than in systems with constant-speed furnaces.

- The insulating sleeve will also provide air sealing to the runout ducts as a bonus, eliminating any need to remove existing external insulation to access these ducts for sealing. 
A way to think about this is to realize that the runouts generally have much higher surface-to-volume ratios than the trunks, which means that the ducted air gets its maximum exposure to conductive losses when it is in the runouts. In the trunks, the air streams destined for the various rooms of the house are like puppies huddled together for warmth, whereas in the runouts each air stream is "on its own" in this regard, like a puppy that has been separated from its littermates.

Under this strategy, any work on the trunk ducts would still need to be addressed in the conventional manner. It should be kept in mind, though, that trunks are often more accessible than the runouts, both because they are more centrally located in the zone containing the ducts and also because the total distance of "technician crawl" required to reach them is usually much less than for the more spread-out runout ducts.

The remainder of this report addresses three issues:

- Relative cross-sectional areas of trunks vs. runouts in typical housing.

- Thermal efficacy of internal insulation in various duct retrofit protocols..

- A possible way to install internal insulating sleeves in runout ducts of circular cross section.

\section{PROPORTIONS OF DUCT SURFACE IN TRUNKS AND RUNOUTS}

Measurements of the duct system configurations were made in eleven singlefamily homes in Long Island, New York. These data were analyzed to determine the proportions of duct surface area represented in trunk ducts and plenums, on the one hand, and in runouts, on the other. Table 1 displays the results.

Table 1. Distribution of Supply Duct Surface Areas Outside Conditioned Space in Eleven Single Family Homes

\begin{tabular}{|l|l|l|l|l|l|l|}
\hline $\begin{array}{l}\text { House } \\
\text { No. }\end{array}$ & $\begin{array}{l}\text { Heated } \\
\text { Area } \\
\left(\mathrm{ft}^{2}\right)\end{array}$ & $\begin{array}{l}\text { Supply } \\
\text { Runouts }\end{array}$ & $\begin{array}{l}\text { Duct Surface in } \\
\text { Runouts }\left(\mathrm{ft}^{2}\right)\end{array}$ & $\begin{array}{l}\text { Duct Surface in } \\
\text { Trunks, etc. }\left(\mathrm{ft}^{2}\right)\end{array}$ & $\begin{array}{l}\text { Area } \\
\text { Ratio** }\end{array}$ & $\begin{array}{l}\text { Percent } \\
\text { Runout }\end{array}$ \\
\hline 1 & 1115 & 11 & 143 & 126 & 0.24 & 53 \\
\hline 2 & 1800 & 15 & 287 & 258 & 0.30 & 53 \\
\hline 3 & 1600 & 18 & 402 & 203 & 0.38 & 66 \\
\hline $6 \mathrm{~A}$ & 1284 & 14 & 272 & 198 & 0.37 & 58 \\
\hline $6 \mathrm{~B}$ & 990 & 9 & 286 & 14 & 0.32 & 94 \\
\hline 7 & 1303 & 10 & 351 & 141 & 0.38 & 71 \\
\hline 9 & 1502 & 16 & 222 & 237 & 0.31 & 48 \\
\hline 10 & 2603 & 21 & 447 & 419 & 0.33 & 52 \\
\hline 12 & 2123 & 18 & 322 & 257 & 0.27 & 56 \\
\hline 14 & 729 & 6 & 127 & 88 & 0.29 & 59 \\
\hline 15 & 1476 & 7 & 169 & 201 & 0.25 & 46 \\
\hline
\end{tabular}

* Skipped house numbers were either not single family, had ducts in conditioned space, had non-circular runouts, or data were lacking. House 6 had separate systems serving each of the two main floors.

**Supply duct surface area divided by heated floor area. 
Leaving out System 6B, which is an "octopus" rather than a trunk-and-branch system, the average percentage of duct surface area that is in runouts is $56 \%$. Although this is a very restricted sample and should be supplemented by data from other regions, it lends some credibility to the expectation that runouts may comprise at least half of the duct surface area in a typical home. The remaining discussion will be based on this expectation.

\section{INTERNAL VS. EXTERNAL INSULATION}

The following duct insulation cases will be considered:

1. As-found system running at full capacity and airflow.

2. As-found system running at half capacity and airflow.

3. System as in (2) above with insulation added to runouts:

$\begin{array}{ll}- & 1 / 2 " \text { interior } \\ \text { - } & 3 / 4 \text { " interior } \\ \text { - } \quad 1 \text { " interior } \\ \text { - } \quad \text { " exterior (R-4 duct wrap) } \\ \text { - } \quad 1 / 2 \text { " interior and 2" exterior }\end{array}$

4. Selected cases from Group 3 above with supply trunks also refitted by sealing $2 / 3$ of the leaks and adding 2 " (R-8) duct wrap to exterior

5. The cases as in Group 4 above with return ducts also refitted to the same level as the supply trunks.

\section{HEAT LOSS FROM A BENCHMARK DUCT SYSTEM}

This section describes the benchmark duct system used to calculate heat losses in the ducts, with reference to ASHRAE Standard 152P (ASHRAE 2001). The details of the calculation are given in the appendix.

In order to benchmark the efficacy of various insulation strategies in a duct system, let us take as an example case a house with $2000 \mathrm{ft}^{2}$ of conditioned floor area. The house is heated and cooled with a forced-air system whose size was driven by the specification of a 3-ton $(36,000 \mathrm{Btu} / \mathrm{h})$ air conditioner. At a nominal $400 \mathrm{cfm}$ per ton, this requires the capability of moving $1200 \mathrm{cfm}$ of air through the duct system. The furnace in the as-found system will be assumed to have a thermal output of $65000 \mathrm{Btu} / \mathrm{h}$, consistent with a $50^{\circ} \mathrm{F}$ temperature rise. It is to be replaced with a modulating furnace whose maximum capacity is the same as that in the as-found system and which has a turndown ratio of 2 . The system airflow with the modulating furnace will be assumed to scale with the heat output, maintaining a constant temperature rise through the unit.

ASHRAE Standard 152P has a provision for a "default" duct surface area, which for supply ducts is $27 \%$ of the conditioned floor area. This is intended to represent a "typical" duct system for cases where the actual surface area was not measured. If we use this typical value as a benchmark, the whole duct system has $540 \mathrm{ft}^{2}$ of surface area. If this is divided between trunks and runouts in a proportion consistent with the findings of the previous section, this would result in approximately $240 \mathrm{ft}^{2}$ of trunk ducts and 
$300 \mathrm{ft}^{2}$ of runouts. In order to get a concrete visualization of this, it would be consistent with a duct system that had two trunk ducts emerging from the furnace, each being $25 \mathrm{ft}$ long and with a $12 \mathrm{in.}$ X $14.4 \mathrm{in}$. cross section. The runouts might be twelve in number, six on each of the two trunk ducts, 6 in. diameter and $16 \mathrm{ft}$ in length. Of course, many other configurations would also be consistent with the overall surface area parameters.

There are no default duct leakage rates in ASHRAE Standard 152, although at one time a set of defaults equal to $17 \%$ of system fan flow on each side of the system were proposed on the basis of stock characterization research performed in California. In this study, it will be assumed that the as-found system has leakage (to/from outside) equal to $10 \%$ of fan flow, or $120 \mathrm{cfm}$, on each side of the system.

Another important parameter is the temperature difference between the ducts and the space surrounding them. In this report, this is assumed to be $30^{\circ} \mathrm{F}$ on both the supply and return sides. This is consistent with a duct zone temperature of $\sim 40^{\circ} \mathrm{F}$ if the temperature inside the house is $70^{\circ} \mathrm{F}$. This would be a reasonable seasonal average in a northern U.S. climate and ducts in a ventilated attic or crawl space.

The insulating material will be assumed to have an R-value of 4 per inch, as characterized in a flat-plane application such as a house wall or the wall of a rectangular duct.

Two major assumptions were made that affect duct leakage under the various insulation and equipment conditions studied. These are:

1. Application of internal insulation to the runouts stops any leaks occurring in that portion of the duct system.

2. Internal insulation causes the pressures in the duct system to change, because of the reduced cross sectional area available for airflow.

How these assumptions are applied is discussed more fully in the Appendix.

\section{IMPACT OF DUCT AND EQUIPMENT PARAMETERS}

With these assumptions in place, we are now in a position to calculate the impact on $\mathrm{DE}$ of furnace modulation using various alternative insulation strategies. The calculations were done using the version of ASHRAE Standard 152P resident on the Lawrence Berkeley National Laboratory (LBNL) Web site (http://ducts.lbl.gov) at the time these calculations were performed, i.e., late 2001. Although the researchers at LBNL are currently revising this calculator in line with changes in the standard, it is not expected that these changes would affect the results reported here, because the equations that are used in the Appendix are not being altered.

\section{Modulating Furnace in the As-Found System}

Under the assumptions outlined above, the as-found system with furnace running at full capacity was found to have a delivery effectiveness (DE) of 68.4\%. When the furnace is turned down to its minimum capacity, the airflow decreases by $50 \%$ but the duct leakage decreases by even more, from $120 \mathrm{cfm}$ to $52 \mathrm{cfm}$, because the 0.6 power variation of leakage with pressure exceeds the 0.5 power variation of airflow with pressure. The a- 
factors therefore increase somewhat when the capacity is turned down, but this effect is overwhelmed by the drop in the B factors, resulting in a DE of $55.5 \%$.

The drop in $\mathrm{DE}$ is about 13 percentage points, but the percentage impact on fuel use is even greater. Everything else being equal, fuel consumption will increase by $23.3 \%$ at the minimum capacity and airflow rate, compared with that at the maximum. As has already been indicated, the modulating furnace may be more efficient than the model it is replacing, and some benefit in distribution efficiency may be expected from reduced cycling with the modulating furnace. Still, an efficiency penalty anything like that indicated above is a tremendous burden to bear for any technology, and it provides strong incentive to try to correct it.

\section{Interior Insulation in the Supply Runout Ducts}

The obvious answer to this problem is to upgrade the duct system. The idea behind this report was that it might be possible, by means of a relatively simple retrofit on the supply runout ducts alone, to make up for the negative impact on efficiency as shown above. It was hoped that if a simple means could be found to install a layer of insulation inside the runout ducts (accessible from the inside of the house after the registers have been temporarily removed) it might become common practice in the industry.

Calculations were performed of these impacts, using the three thicknesses of internal insulation ranging from 0.5 inches to $1.0 \mathrm{inch}$. The internal insulation material was assumed to have the same thermal conductivity as the external insulation considered above, namely $0.02 \mathrm{Btu} / \mathrm{h}-\mathrm{ft}-^{\circ} \mathrm{F}$.

Under these assumptions, the DE of the system under full turndown $(600 \mathrm{cfm})$ operation rises significantly. Recall that the $\mathrm{DE}$ in the as-found system dropped from $68.4 \%$ to $55.5 \%$ when the furnace output and airflow rate were cut in half. With the added insulation, the DE for the half-capacity and airflow system rises from $55.5 \%$ to:

- $63.3 \%$ for $1 / 2$ " inside insulation;

- $64.6 \%$ for $3 / 4$ " inside insulation;

- $65.6 \%$ for 1 " inside insulation.

The use of this inside insulation decreases the energy penalty of furnace modulation from $23 \%$ to somewhere in the $4 \%-8 \%$ range, depending on the thickness of the insulation. This is a dramatic improvement. True, the negative impact on DE is not completely erased, but most of it is.

For comparison purposes, adding R-4 duct wrap to the outside of the runout ducts would raise the DE only to $61.9 \%$. Adding R-8 duct wrap to the outside of the runouts gives a $\mathrm{DE}$ of $64.2 \%$. The latter figure is in the range of the numbers for inside insulation, so deciding between them becomes a matter of which action is more feasible. It also depends on the external insulation being as effective as indicated by the indicated $\mathrm{R}$-value. There is some evidence that external duct wrap can be less effective than this, possibly due to unintended compression of the insulating material (Andrews 2002). 


\section{Can the Duct System Be Made Better Still?}

The conclusion from the above analysis is that in the benchmark duct system it is possible to counteract most of the negative impact of the reduced flow rate through the introduction of interior insulation in the runout ducts. The logical follow-on question, though, is "Why stop there?" Perhaps the decision to install a modulating furnace can be turned into an advantage by improving the duct system sufficiently so that its performance is much superior to what it was using the old furnace.

We have yet to consider fixing the supply trunk ducts or any part of the return system. It is likely that in may cases the supply trunk ducts will be easier to reach than the supply runouts. If they are in the attic, they tend to be centrally located under the ridgeboard, where head clearance is greatest, whereas the runouts usually head into the darker, tighter, less accessible portions of the attic, such as under the eaves. If the supply ducts are in a crawl space, there will be no more head clearance in one place than in another, but the amount of crawling required to reach the trunk ducts will be much less than that required to reach the entire system.

Consider our benchmark duct system with its furnace in the middle of the crawl space, two branch trunks leading out $25 \mathrm{ft}$ in opposite directions along the long axis of the house, and 12 runouts, each $16 \mathrm{ft}$ in length. To reach the trunk ducts requires $2 \times 25$ $=50 \mathrm{ft}$ of crawling by the technician, but to reach the whole supply system requires this $50 \mathrm{ft}$ plus $12 \times 16=242 \mathrm{ft}$ of crawling, nearly five times more! This fact, combined with the often-found situation that the runouts are either very close to joists and subflooring above, or worse, are in panned joists, adds appeal to a retrofit strategy that confines to the trunks the requirement of physically accessing the ducts.

The judgment was also made that $1 / 2$-inch inside insulation is likely to be much easier to work with than anything thicker. With this in mind, the impact on DE of installing 1/2-inch insulation inside the runouts together with sealing and external wrapping of supply trunks was considered. Specifically, it was assumed that the supply trunks would be retrofitted by pulling away the existing insulation, finding and sealing two-thirds of the leaks, replacing the existing insulation, and finally wrapping the whole with an additional R-8 duct wrap. In addition to its insulating value, the added duct wrap makes it unnecessary to consider aesthetics in the process of opening and replacing the existing insulation, as long as it is replaced in a manner that covers the ducts.

This retrofit protocol was found to increase the $\mathrm{DE}$ under low-capacity operation to $73.7 \%$. Not only is this a dramatic improvement on the $55.5 \% \mathrm{DE}$ that will result if nothing is done, it is even a worthwhile improvement on the original $68.4 \% \mathrm{DE}$ in the asfound system. Fuel use under the benchmark conditions would be reduced by $7 \%$.

Note that the $73.7 \%$ efficiency is under low-flow operation, whereas the original $68.4 \%$ was at the full capacity and airflow. For those times when the modulating furnace happens to be running at full capacity, the DE with the proposed strategy will actually rise to over $82 \%$.

It is possible to do still better. If the return duct system can be retrofitted in the same manner as the supply trunks, the DE now rises to $79.0 \%$ at half capacity and 
airflow. This results in a $13 \%$ reduction in fuel use, relative to the original system, even if the furnace runs at low flow all the time. Manual sealing and insulation of the return ducts (assuming there are return ducts, which is not always the case) may be simpler than on the supply side, since often there is only one return register and the return duct is likely to be relatively short. And once again it should be noted that this does not include any benefit from reduced cycling or from improved efficiency of the modulating furnace itself.

In either of the above two cases, going from $1 / 2$-inch to $3 / 4$-inch interior insulation in the runouts adds 2 percentage points to the $\mathrm{DE}$, for an additional $2.5 \%$ reduction in fuel use.

This benchmarking study can be summarized in the following way:

- Simply mating a modulating furnace to a typical existing duct system will cause serious deterioration in thermal distribution efficiency.

- Most of this negative impact can be erased without requiring technicians to physically interact with the ductwork if a way can be found to install an insulating sleeve in the supply runout ducts.

- Combining this action with conventional retrofits of the more-accessible supply trunks (and perhaps the return ducts as well) can result in a thermal distribution efficiency with the modulating furnace at low capacity that is significantly better than in the as-found system at high capacity.

\section{CONCEPTUAL DESIGN OF A PRACTICAL SYSTEM FOR INTERNAL INSULATION RETROFIT}

As has been indicated above, the duct retrofit strategy envisioned in this report involves the use of insulating sleeves installed inside the supply runout ducts. But as with the fairy-tale mice who were stumped by the question of how to put the bell on the cat, the question remains here of how to get these sleeves into the ducts.

A definite answer to how (or even whether) this can be done cost-effectively must await experimentation and prototyping. There is, however, a conceptual approach that could serve as an initial basis for such a project. The basic elements of this approach are shown schematically in Figure 1.

In this approach, insulating sleeves would be manufactured in cross-sectional profiles to fit most sizes of American ductwork, and in a sufficient number of lengths that they could be cut to the exact required length with a minimum of waste. Conceptually, they would be made from a material with the general consistency and flexibility of the bubble-wrap material that is commonly used to cushion fragile shipments. A degree of elasticity would probably need to be engineered into the material so that it could fit around elbows successfully. An adhesive material would be factory-applied to the inside of these sleeves, with the requirement that its chemistry permit it to remain tacky until it is exposed to the air. (They could be packed for shipment in sealed plastic bags purged with nitrogen.) 
The first step of the installation process would be to determine the length of the runout duct and cut the insulating sleeve to the proper length to fit. A device to facilitate this from inside the living space could be constructed (perhaps some kind of "crawler" on a tether whose free end is held inside the room) but its detailed design is beyond the scope of this report.

Next, the register is removed, and one end of the sleeve is rolled back on itself to expose a short length of the inside of the sleeve. The exposed inside of the sleeve is attached to the inside of the duct at the lip of the register. This is shown schematically in the top drawing of Figure 1. The idea is that the inside of the sleeve, with its adhesive, will upon installation become the outside, facing the inside of the duct.

The next stage of installation is the application of negative pressure to the trunk duct. An adjustable fan attached at the return register would serve this function. This would keep the whole operation within the living space. The far end of the sleeve would be closed off using a temporary closure that would either "pop off" at the completion of installation or could be removed with a light tug on a string attached to the closure, said string trailing behind the end of the sleeve inside the duct as it is sucked in.

Multiple sleeves might be installed simultaneously, or they might be done one at a time. In either case, any registers serving ducts that are not being fitted with sleeves would need to be sealed off during the "sucking in" process.

The initiation of this stage is depected in the middle drawing of Figure 1. The completed installation would be as shown in the bottom drawing of the figure.

\section{CONCLUSION}

A benchmark analysis indicates a significant loss of thermal distribution efficiency consequent to furnace operation at flow rates lower than those for which the duct system was originally intended. This impact may be largely mitigated through the use of a scheme for insulating supply runout ducts using insulating sleeves installed from within the conditioned space. Combining this with a conventional retrofit of the supply trunks and return ducts (which are generally more accessible) can further improve duct efficiency. Exploratory development of the concept appears to be warranted.

\section{ACKNOWLEDGMENT}

This work was supported by the Office of Building Technology, State and Community Programs, U.S. Department of Energy.

\section{REFERENCES}

Andrews, J.W. 2002. Effect of Airflow and Heat Input Rates on Duct Efficiency Submitted to ASHRAE Transactions.

Andrews, J.W. and R.F. Krajewski 1985. Forced-Air Thermal Distribution Systems in Small Buildings: R\&D Planning Studies in Zoning and System Losses. BNL 51968, pp. $42-44$. 
ASHRAE 2001. Standard 152P, Method of Test for Determining the Design and Seasonal Efficiencies of Residential Thermal Distribution Systems. Atlanta, Ga., American Society of Heating, Refrigerating, and Air-Conditioning Engineers, Inc.

ASHRAE 1989. Handbook of Fundamentals, p. 32.6. Atlanta, Ga., American Society of Heating, Refrigerating, and Air-Conditioning Engineers, Inc.

Walker, I.S. 2002. Sensitivity of Forced Air Distribution System Efficiency to Climate, Duct Location, Air Leakage, and Insulation. LBNL 43371.

\section{APPENDIX. HEAT LOSS FROM A BENCHMARK DUCT SYSTEM}

This appendix reviews the equations used to calculate heat losses in ducts, with reference to ASHRAE Standard 152P (ASHRAE 2001), and also the assumptions made concerning the influence of various insulation schemes on the leakage pressures within the duct system. The benchmark duct system discussed in the main report is used, with parameters summarized as follows:

- Conditioned floor area $=2000 \mathrm{ft}^{2}$

- Airflow rate at full capacity $=1200 \mathrm{cfm}$

- Furnace capacity at high setting $=65000 \mathrm{Btu} / \mathrm{h}$

- Furnace turndown ratio $=2$

- Supply duct surface area $=540 \mathrm{ft}^{2}$ of which $240 \mathrm{ft}^{2}$ in trunk ducts and $300 \mathrm{ft}^{2}$ in runouts

- Supply leakage at full airflow $=120 \mathrm{cfm}$

\section{Thermal Loss Calculations}

Analysis of the relative effectiveness of internal vs. external insulation in a round duct requires use of the heat-flow equations for an insulated pipe. These can be expressed in terms of a general equation relating heat flow $(\varphi$, in Btu/h) to the overall heat-transfer coefficient (UA, in Btu/h- $\left.{ }^{\circ} \mathrm{F}\right)$ exposed to an inside-outside temperature difference $(\Delta \mathrm{T}$, in $\left.{ }^{\circ} \mathrm{F}\right)$, togther with a specific formula giving the UA for the geometry in question:

$$
\begin{aligned}
& \varphi=\mathrm{UA} \Delta \mathrm{T} \\
& \mathrm{UA}=2 \pi \mathrm{kL} / \ln \left(\mathrm{r}_{2} / \mathrm{r}_{1}\right)
\end{aligned}
$$

where $\mathrm{k}$ (in Btu/ft-h- ${ }^{\circ} \mathrm{F}$ ) is the thermal conductivity of the insulating material, $\mathrm{L}$ is the length of the duct, and $r_{1}$ and $r_{2}$ are the inner and outer radii, respectively, of the insulated layer of the duct. It is important to note here that, once the length of the duct and the thermal conductivity of the insulating material are determined, the UA depends only on the ratio of the inner and outer radii of the insulation, not on their absolute values. (This is a somewhat simplified analysis in that the influence of internal and external film coefficients is ignored.)

What is of interest here is the fraction of the heat supplied to the ducts that is lost by the air on its way through them. The relevant parameter that emerges from such an 
analysis is the one that is labeled " $\mathrm{B}_{\mathrm{s}}$ " or " $\mathrm{B}_{\mathrm{r}}$ " in ASHRAE Standard 152P. These B factors, with the subscripts referring to supply or return ducts, respectively, in the standard, are given by the following formula:

$$
B=\exp \left[-U A /\left(60 Q \rho c_{p}\right)\right]
$$

where $\mathrm{Q}$ is the volume air flow rate in cubic feet per minute ( $\mathrm{cfm}), \rho$ is the air density $\left(0.075 \mathrm{lbm} / \mathrm{ft}^{3}\right.$ at standard conditions), and $c_{p}$ is the specific heat at constant pressure $\left(0.24 \mathrm{Btu} / \mathrm{lbm}-{ }^{\circ} \mathrm{F}\right)$. (This formula appears slightly different from the one in Standard $152 \mathrm{P}$, in that $\mathrm{UA}$ is used instead of $\mathrm{A} / \mathrm{R}$, but the result is the same.)

The impact of duct leakage in Standard 152 is captured through parameters labeled $a_{s}$ and $a_{r}$. These so-called "a-factors" represent the fraction of air that does not leak on the supply and return sides of the duct system, respectively. That is,

$$
\mathrm{a}=\left(\mathrm{Q}_{\mathrm{e}}-\mathrm{Q}_{\text {leak }}\right) / \mathrm{Q}_{\mathrm{e}}
$$

where $\mathrm{Q}_{\text {leak }}$ is the leakage flow (to or from outside) on the side of the duct system whose a-factor is being considered and $Q_{e}$ is the airflow rate at the system fan.

The $\mathrm{a}$ and $\mathrm{B}$ factors are inputs into the equation for delivery effectiveness (DE) ${ }^{2}$ but it is not the only determinant of $\mathrm{DE}$. Of equal importance are the temperatures experienced inside and outside the ductwork. The heating-mode equation for DE (from ASHRAE Standard 152P) is:

$$
D E=a_{s} B_{s}-a_{s} B_{s}\left(1-B_{r} a_{r}\right) \Delta t_{r} / \Delta t_{e}-a_{s}\left(1-B_{s}\right) \Delta t_{s} / \Delta t_{e}
$$

where $\mathrm{a}_{\mathrm{s}}$ and $\mathrm{a}_{\mathrm{r}}$ are leakage factors, for the supply and return sides, respectively, as defined in Equation 4. The factor $\Delta t_{r}$ is the temperature difference between the house interior and the zone surrounding the return ducts, while $\Delta t_{s}$ is a similar factor for the supply ducts. The factor $\Delta t_{\mathrm{e}}$ is the temperature rise of the air as it passes through the furnace or heat pump.

For benchmarking purposes, it will be assumed that $\Delta t_{\mathrm{r}}=\Delta \mathrm{t}_{\mathrm{s}}=30^{\circ} \mathrm{F}$. This is consistent with a duct zone temperature of $\sim 40^{\circ} \mathrm{F}$ if the temperature inside the house is $70^{\circ} \mathrm{F}$. This would be a reasonable seasonal average in a northern U.S. climate and ducts in a ventilated attic or crawl space.

The insulating material will be assumed to have an R-value of 4 per inch, if characterized in a flat-plane application such as a house wall or the wall of a rectangular duct. For round ducts, we need to translate this into a thermal conductivity, which is done using:

$$
k=d / R
$$

where $\mathrm{d}$ is the insulation thickness (in $\mathrm{ft}$ ) and $\mathrm{R}$ is the thermal resistance (in $\mathrm{ft}^{2}-\mathrm{h}^{-0} \mathrm{~F} / \mathrm{Btu}$ ). For the case considered here, $\mathrm{k}=.083 / 4=0.02$.

${ }^{2} \mathrm{DE}$ is defined as the ratio of heat delivered by the ducts into the living space to the heat input to the ducts by the furnace. 


\section{Leakage Impacts}

Two major assumptions were made that affect duct leakage under the various insulation and equipment conditions studied. These are:

1. Application of internal insulation to the runouts stops any leaks occurring in that portion of the duct system.

2. Internal insulation causes the pressures in the duct system to change, because of the reduced cross sectional area available for airflow.

For the base case system, it was assumed that the total pressure drop over the supply duct system is $50 \mathrm{~Pa}$. In a typical duct system, most of the pressure drop will be caused by such things as fittings, bends, equipment coils and heat exchangers, registers, and abrupt changes in cross section. The pressure drop caused by friction losses in straight sections will generally be on the order of a few pascals.

For our purposes, however, it is necessary to estimate the impact on these losses of constricting the runouts with internal insulation. To do this, the ASHRAE friction chart (ASHRAE 1989) was employed, providing the information in Table 2.

Table 2. Pressure Loss from Friction in Runout Ducts

\begin{tabular}{|c|c|c|c|}
\hline Airflow and Pipe Length & Pipe Diameter & $\begin{array}{l}\text { Friction Loss } \\
\text { in. water per } 100 \mathrm{ft}\end{array}$ & $\begin{array}{l}\text { Total Friction } \\
\text { Loss, } \mathrm{Pa}\end{array}$ \\
\hline \multirow[t]{4}{*}{$100 \mathrm{cfm}$ through $16 \mathrm{ft}$ pipe } & $6.0 \mathrm{in}$. & 0.08 & 3.2 \\
\hline & $5.0 “$ & 0.20 & 8 \\
\hline & 4.5 “ & 0.35 & 14 \\
\hline & $4.0 "$ & 0.60 & 24 \\
\hline \multirow[t]{4}{*}{$50 \mathrm{cfm}$ through $16 \mathrm{ft}$ pipe } & 6.0 in. & 0.025 & 1.0 \\
\hline & $5.0 "$ & 0.06 & 2.4 \\
\hline & $4.5 “$ & 0.12 & 4.8 \\
\hline & $4.0 “$ & 0.18 & 7.2 \\
\hline
\end{tabular}

It is now possible to estimate the pressure at the supply plenum under various conditions. If there is no interior insulation, then when the airflow rate is cut in half, the pressure at any point in the duct should drop to one-fourth of its original value, because of the relation

$$
\mathrm{Q}=\mathrm{C} \mathrm{P}^{\mathrm{n}}
$$

where $\mathrm{Q}$ is airflow, $\mathrm{P}$ is pressure, and $\mathrm{C}$ is a constant, and $\mathrm{n}=0.5$ for flow through a wide orifice or duct. So the plenum pressure at $50 \mathrm{cfm}$ airflow and no interior insulation should be $\sim 12.5 \mathrm{~Pa}$. 
Where there is interior insulation, the plenum pressure at $50 \mathrm{cfm}$ airflow was estimated by adding the difference between the friction loss through 6 in. pipe and that through the pipe having a reduced diameter appropriate to the particular insulation level. This leads to:

- for $1 / 2 \mathrm{in}$. interior insulation, $12.5+2.4-1.0=13.9 \mathrm{~Pa}$

- for $3 / 4 \mathrm{in}$. interior insulation, $12.4+4.8-1.0=16.3 \mathrm{~Pa}$

- for 1 in. interior insulation, $12.4+7.2-1.0=18.7 \mathrm{~Pa}$.

The impact of these parameters on the duct leakage rate was estimated as follows. First, the average leakage pressure in the trunk ducts was assumed to equal $75 \%$ of the plenum pressure, while the average leakage pressure in the runouts was assumed to equal $25 \%$ of the plenum pressure. Combined with the previously discussed breakout of $45 \%$ of the duct surface area being in the trunks and $55 \%$ in the runouts, this leads to $\sim 60 \%$ of the leakage occurring in the trunks and $40 \%$ in the runouts. ${ }^{3}$

Starting with our base assumption of $120 \mathrm{cfm}$ leakage in the benchmark system with $1200 \mathrm{cfm}$ airflow, we obtain the leakage rate for the same system with $600 \mathrm{cfm}$ of airflow by noting that the duct leakage at any pressure is given by Equation 7 with $\mathrm{n}=0.6$. The ratio $(12.5 / 50)^{0.6}=0.435$, which when multiplied by 120 yields 52 . The leakage rate in the benchmark duct system with low flow is therefore set at $52 \mathrm{cfm}$. The same value is used for systems where only external insulation is added, the assumption being that external insulation produces no measurable reduction in leakage.

Where internal insulation is used, two effects are factored in. The first is an assumed elimination of that portion of the leakage that had come from the runouts, since the internal insulation is forced against the inside surface of the ducts, presumably with some kind of bonding agent, to form a seal. In the absence of any other factor, this would reduce the leakage to that in the trunks, i.e., $60 \%$ of $52 \mathrm{cfm}$ or $31 \mathrm{cfm}$. However, the slight increase in pressure in the trunks caused by constriction of the runouts leads to slightly higher values. These are $33 \mathrm{cfm}$ for $1 / 2 \mathrm{in}$. internal insulation; $37 \mathrm{cfm}$ for $3 / 4 \mathrm{in}$. insulation; and $40 \mathrm{cfm}$ for $1 \mathrm{in}$. insulation. An additional set of cases was considered, in which the internal insulation of the runouts was combined with conventional sealing and insulation of the trunks, assumed to seal $2 / 3$ of the trunk leaks. These cases would then reduce the total leakage rates to 11,12 , and $13 \mathrm{cfm}$ for $1 / 2$ in., $3 / 4$ in., and 1 in. internal runout insulation, respectively.

${ }^{3}$ This split is obtained by pro-rating as follows. Trunk leakage is proportional to $0.75^{0.6}$ $\mathrm{X} 0.45=0.38$. Runout leakage is proportional to $0.25^{0.6} \times 0.55=0.24$. Then, 0.38 is $\sim 60 \%$ of the total $0.38+0.24$, while 0.24 is $\sim 40 \%$ of this sum. 


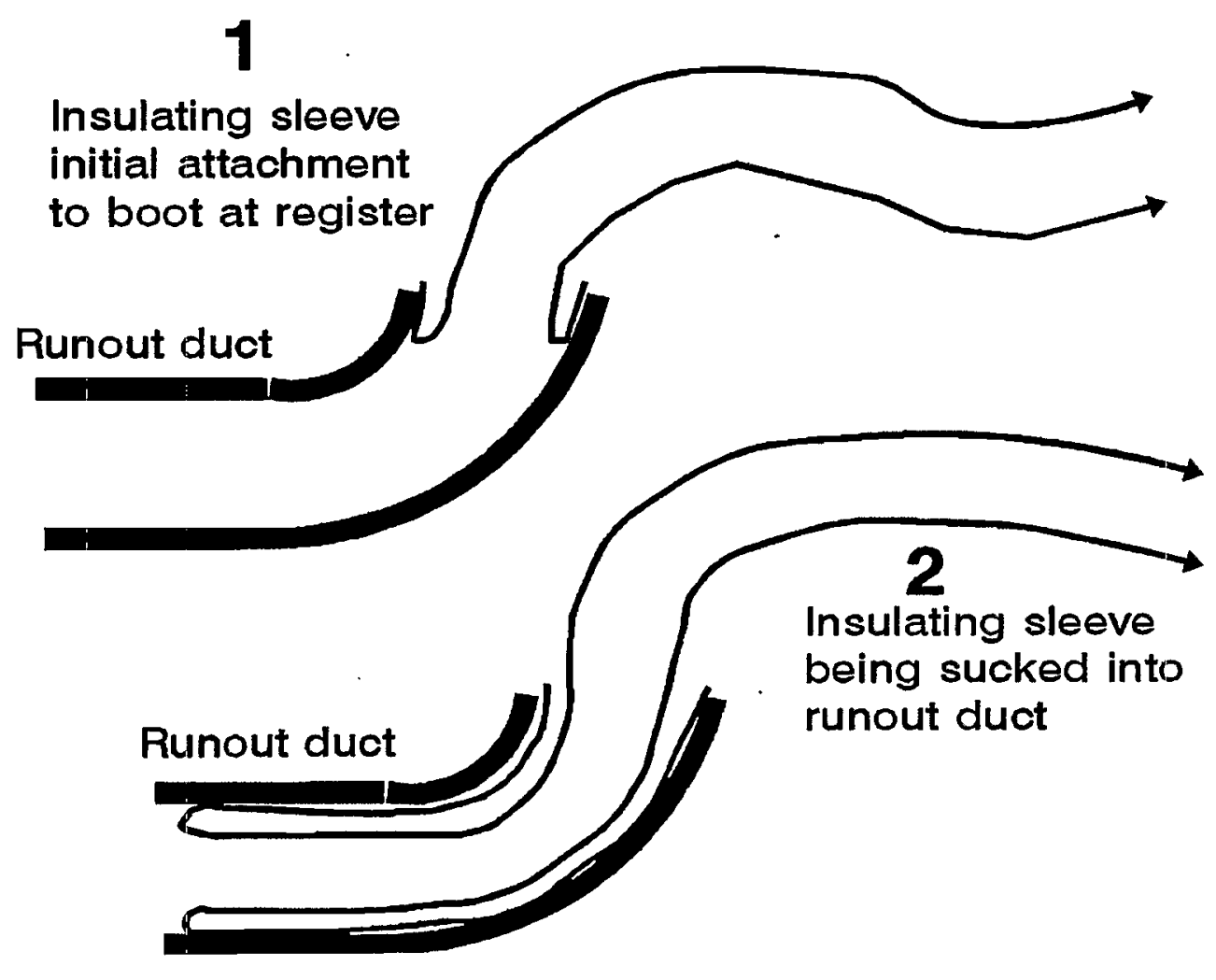

Trunk

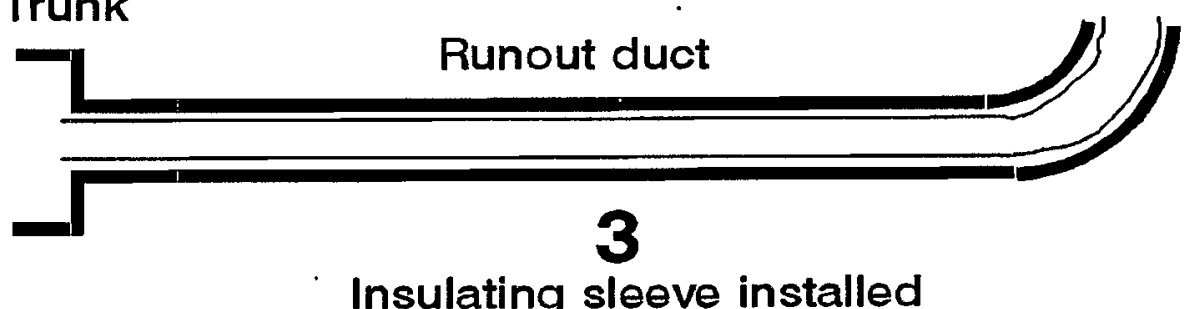

Insulating sleeve installed

FIGURE 1. INSULATING SLEEVE INSTALLATION SCHEMATIC 